\title{
STRESS, DEPRESSION, ANXIETY, AND COPING STRATEGIES OF PARENTS OF INTELLECTUALLY DISABLED AND NON-DISABLED CHILDREN
}

\author{
Naeema Arzeen', Erum Irshad', Saima Arzeen'1, Syed Mubashir Shah² \\ ${ }^{1}$ Department of Psychology, University of Peshawar - Pakistan \\ ${ }^{2}$ Department of Psychiatry, Combined Military Hospital, Peshawar - Pakistan
}

\begin{abstract}
Objectives: The current study was aimed to investigate the differences on stress, depression, anxiety, and coping strategies of parents of intellectually disabled and non-disabled children.
\end{abstract}

Material and Methods: Sample consisted of parents $(\mathrm{N}=300)$ that was further divided into two groups (parents of intellectually disabled children; $n=150$ and parents of non-disabled children; $n=150$ ). Data was collected from Peshawar, Islamabad, Rawalpindi, and Wah Cantt; for this purpose consent form, demographic information sheet, along with two standardized scales Depression Anxiety Stress Scale (DASS-42) and Brief COPE were given to the parents of disabled children and non-disabled children.

Results: The study shows that significant mean differences were observed on DASS; intellectually disabled children's parents reported higher stress, depression, and anxiety than non-disabled children's parents. Non-significant mean differences were observed in subscale of Brief COPE, except on self-blame in which parents of intellectually disabled children scores were higher as compared to the parents of non-disabled children.

Conclusion: The findings depicted that disability raises extra burden on the parents, which promoted stress, depression, and anxiety. After developing these psychopathologies, parents became over sensitive and got emotional and used emotion based coping patterns. They easily blame themselves for the disability and all the problems which are directly linked with it.

Keywords: Stress, Depression, Anxiety, Coping strategies, Intellectually disabled, Non-disabled

This article may be cited as: Arzeen N, Irshad, Arzeen S, Shah SM. Stress, Depression, Anxiety, and Coping Strategies of parents of Intellectually Disabled and Non-Disabled Children. J Med Sci 2020 October;28(4):380-383

\section{INTRODUCTION}

Birth of a child affects the overall family dynamics; it brings joy, happiness, hopes, and mixed feelings for the parents. In case of disabled children, disability and cognitive problems bring extra needs and demands for the parents; because of continuous pressures, parents develops stress, depression, and anxiety. ${ }^{1,2}$ Most prevalent disorders are depression and anxiety in population; disability is linked with behavioral issues that can lead to distress in caregivers. ${ }^{3,4}$ Psychiatric symptoms promote lower ability for dealing with stressors in the parents of disabled children as compared to those parents having non-disabled children. ${ }^{5,6}$ Stress is a negative affective state that occurs after the threatful events which are uncontrollable and indi-

\section{Correspondence}

Naeema Arzeen

Department of Psychology, University of Peshawar -

Pakistan

Email: naeemaarzeen@yahoo.com

Cell: +92-334-5543862

Date received: $21-04-2020$

Date revised: $\quad 15-05-2020$

Date accepted: $15-12-2020$ viduals identify problems how they respond and attempt to cope with. ${ }^{7}$ Depression is the most prevalent disorder with multiple symptoms (sad mood, sleep problems, lack of concentration, loss of energy, and social life disturbance) ${ }^{8}$ Anxiety is a negative affective state because of the disable children' parents develop the symptoms of excessive worries, anxiousness, and sleep related problems. ${ }^{8}$ Coping is the ability of facing and managing the stressful situations. All parents (disabled children and non-disabled children) applies various techniques for dealing with such situations but it may varies according to the demands of their children. Strategies can be emotion-focused and/or problem-focused such as active coping, planning, social support, emotional support, acceptance, religion, positive reinterpretation, behavioral disengagement, and denial. ${ }^{9}$

Parenting is a tough process as previous studies results indicates that parents with special children having more stress, depression, and anxiety because of extra burden than parents of non-disabled children. ${ }^{6,10}$ In Asian countries, as previous literature indicates that intellectually disabled children parents reported mores anxiety and depression. ${ }^{11,12}$ 
Stress, Depression, Anxiety, And Coping Strategies Of Parents Of Intellectually Disabled And Non-Disabled Children.

A recent study was conducted in Pakistan, in which researchers approached the intellectually disabled children parents and investigate their coping patterns. The results of the study showed that mostly parents used self-distraction, behavioral disengagement, and venting of emotions. Most of the parents' uses emotion-based coping strategies (venting of emotions, self-blame, and denial for dealing with disabled children that increases psychiatric illnesses in them. When parents applied problem-focused patterns (behavioral disengagement, positive reframing, active coping, and planning), their level of burden or stressors decreases. ${ }^{1,3}$ Supporting networks are of great concerning element in the lives of parents, as previous studies findings shows that supportive patterns (emotional, social, and financial) increases the parents' well-being (psychological, emotional, mental, and subjective). ${ }^{14,15}$

Keeping in view the higher prevalence of psychopathology in Pakistan, most of the studies focused on stress, depression, and anxiety in intellectually disabled children's parents. Literature indicated that intellectually disabled children's parents had higher level of psychiatric illnesses than parents of other disabilities (physical and chronic illnesses). ${ }^{16}$ These psychopathologies (stress, depression, and anxiety) affects the parents badly and because of this, they are unable to handle the stressful conditions. This study focuses on coping strategies (emotion-focused and problem-focused) of such parents how they deal with such situations in our local context and compared with the parents of non-disabled children.

\section{MATERIALS AND METHODS}

The aim of this study was to investigate the differences in stress, depression, anxiety, and coping strategies among parents of intellectually disabled and non-disabled children. Purposive sampling technique was used in this study, total sample of the study was 300 parents (intellectually disabled children parents; $n=150$ and non-disabled children's parents; $n=150$ ); with age range of 20 to 60 years. Parents of those children who were admitted in special education institutes (mild and moderate level of intellectually disabled children) and main stream schools were approached. For this purpose, initially researcher took the permission from the authorities of special institutes and main stream schools. After the parents' consent, demographic sheet and standardized scales Depression Anxiety Stress Scale (DASS-42) ${ }^{17}$ and Brief COPE ${ }^{18}$ were administered on all parents. After the data collection, data was analyzed on SPSS 21. Descriptives statistics and t-test was computed on all study variables.

\section{RESULTS}

Parents age range between 20 to 60 years (intellectually disabled children parents; $M=37.56$ and non-disabled children parents; $M=34.21$ ).

Further, descriptive statistics (M, SD, a) of intellectually disabled children parents indicates on Depression Anxiety Stress Scale (Mean \pm SD $76.85 \pm 38.09$, $a=0.96$ ) and on Brief COPE (Mean \pm SD $12.71 \pm 6.62, a=0.74$ ). Non-disabled children parents descriptive statistics on Depression Anxiety Stress Scale (Mean \pm SD $59.66 \pm 37.21$, $a=0.90$ ) and on Brief COPE (Mean \pm SD $14.16 \pm 8.03$, $a=0.75$ ). Data is normally distributed and it is fulfilling the assumption of parametric testing.

Table 1 indicates that, on DASS dimensions values are significant (t $(298)=$ depression, 3.48; anxiety, 4.03; stress, $3.44, p<.01$ ). On all scales depression, anxiety, and stress of intellectually disabled children parents scores are higher than non-disabled children parents.

Further, Table 2 indicates the mean differences among the parents' of both groups and results indicates that on COPE dimension self-blame $(t(298)=2.62, p<.01)$ significant differences are observed. Disabled children parents have higher scores than non-disabled children parents on self-blame. On other dimensions of COPE, values are non-significant among both groups of parents.

\section{DISCUSSION}

Previous studies mainly focused on psychological problems while this study focused on how intellectually disabled children cope with these problems. ${ }^{9}$ The findings of the study indicated that parents' of intellectually disabled children had more psychological distress (stress, depression, and anxiety) than non-disabled children's

Table 1: Means, Standard Deviations, and t-values on DASS dimensions among Non-disabled children parents $(n=150)$ and Intellectually Disabled children parents $(n=150)$

\begin{tabular}{|c|c|c|c|c|c|c|c|c|c|}
\hline \multirow[t]{2}{*}{ Subscales } & \multicolumn{2}{|c|}{$\begin{array}{l}\text { Non-disabled } \\
(n=150)\end{array}$} & \multicolumn{2}{|c|}{ Disabled $(n=150)$} & \multirow[t]{2}{*}{$t(298)$} & \multirow[t]{2}{*}{$\mathbf{p}$} & \multicolumn{2}{|c|}{$\mathrm{Cl} \% 95$} & \multirow[t]{2}{*}{ Cohen's d } \\
\hline & $M$ & SD & $M$ & SD & & & LL & UL & \\
\hline Depression & 19.60 & 13.25 & 25.41 & 13.11 & 3.48 & .000 & -8.79 & -2.83 & -.44 \\
\hline Anxiety & 20.70 & 12.40 & 26.48 & 12.58 & 4.03 & .000 & -8.60 & -2.96 & -.46 \\
\hline Stress & 19.36 & 13.70 & 24.95 & 14.58 & 3.44 & .000 & -8.70 & -2.39 & -.39 \\
\hline
\end{tabular}

Note. $\mathrm{Cl}=$ Confidence Interval; LL= Lower Limit; UL= Upper Limit 
Stress, Depression, Anxiety, And Coping Strategies Of Parents Of Intellectually Disabled And Non-Disabled Children.

Table 2: Means, Standard Deviations, and t-values on Brief COPE dimensions among Parents of Non- Disabled $(n=150)$ and Intellectually Disabled Children $(n=150)$

\begin{tabular}{|c|c|c|c|c|c|c|c|c|c|}
\hline \multirow[t]{2}{*}{ Subscales } & \multicolumn{2}{|c|}{$\begin{array}{c}\text { Non-disabled } \\
(n=150)\end{array}$} & \multicolumn{2}{|c|}{ Disabled $(n=150)$} & \multirow[t]{2}{*}{$t(298)$} & \multirow[t]{2}{*}{$p$} & \multicolumn{2}{|c|}{ Cl $95 \%$} & \multirow[t]{2}{*}{ Cohen's d } \\
\hline & $M$ & SD & $M$ & SD & & & LL & UL & \\
\hline Self -Distraction & 3.95 & 1.62 & 4.18 & 1.70 & 1.20 & .22 & -.60 & .14 & .13 \\
\hline Active Coping & 4.51 & 2.14 & 4.26 & 1.91 & 1.06 & .29 & -.21 & .70 & .12 \\
\hline Denial & 4.01 & 1.80 & 4.06 & 1.81 & .25 & .80 & -.46 & .35 & .02 \\
\hline Substance use & 2.94 & 1.35 & 3.11 & 1.56 & 1.02 & .30 & -.50 & .16 & .11 \\
\hline Emotional Supp & 4.53 & 1.45 & 4.42 & 1.74 & .59 & .55 & -.47 & .25 & .06 \\
\hline Instrumental Supp & 4.49 & 1.64 & 4.15 & 1.47 & 1.85 & .06 & -.02 & .68 & .21 \\
\hline $\mathrm{BD}$ & 4.58 & 1.45 & 4.83 & 1.40 & 1.54 & .12 & -.57 & .06 & .17 \\
\hline VOE & 4.45 & 1.68 & 4.15 & 1.60 & 1.58 & .11 & -.07 & .67 & .18 \\
\hline Positive Reframing & 6.07 & 2.05 & 5.62 & 2.20 & 1.84 & .06 & -.93 & .03 & .21 \\
\hline Planning & 5.39 & 1.93 & 5.37 & 1.59 & .11 & .91 & -.37 & .42 & .01 \\
\hline Humor & 5.21 & 1.84 & 4.85 & 2.10 & 1.56 & .11 & -.80 & .09 & .18 \\
\hline Acceptance & 5.36 & 1.86 & 5.26 & 1.70 & .49 & .62 & -.30 & .50 & .05 \\
\hline Religion & 5.48 & 2.06 & 5.57 & 1.85 & .42 & .67 & -.54 & .34 & .04 \\
\hline Self-Blame & 4.51 & 1.99 & 5.08 & 1.77 & 2.62 & .00 & -1.0 & -.14 & -.30 \\
\hline
\end{tabular}

Note.Cl=Confidence Interval; LL=Lower Limit; UL=Upper Limit; BD=Behavioral disengagement; VOE=Venting of Emotions.

parents. Findings were in line with previous literature in which researchers concluded that parents of individuals with intellectual disabilities reported higher distress as compared to non-disabled children's parents. ${ }^{5}$ In Asian countries, studies findings indicated that intellectually disabled children' parents reported more anxiety and depression. ${ }^{11,12}$

The findings of this study stipulate that on selfblame (emotion-focused) coping strategy, significant mean differences were found $(\mathrm{t}(298)=2.62, \mathrm{p}<.01$ ). Intellectually disabled children parents used self-blame for dealing with stress as compared to non-disabled children's parents. Previous studies showed mixed findings regarding the coping strategies (wishful thinking, self-blame, and distancing) of special needs children's parents; such parents scored higher on emotion-based coping patterns that promoted poor strengths and lower well-being. ${ }^{19}$ This is an important aspect that such parents used blaming strategy most of the time that showed they had poor control on handling their children's conditions. Mostly parents' applied emotion-based coping styles and used supportive patterns. ${ }^{13,15}$ Non-disabled children parents have had better patterns and opportunities in their surroundings and involved themselves in other positive activities than parents of disabled children.

Although, the present study was done with utmost input there are certain limitations that are noteworthy. Researcher focused on stress, depression, and anxiety and ignored the other psychopathologies; future researchers need to consider this for more findings. Due to time con- straints, cross-sectional research design was used while further longitudinal designs should be planned for investigating in-depth knowledge regarding the disability. Literature is very limited with regard to coping patterns of such parents so this study tried to fill the gaps in knowledge within local context but further researches must add the role of specific coping styles and its relation to psychopathology. This study highlighted the role of coping strategies which are mostly implemented by the parents for handling the situations. Mental health professionals will plan strategies according to the coping styles which are predominantly prevailing in this society.

\section{CONCLUSION}

The parents of intellectually disabled children had more stress, depression, and anxiety as compared to non-disabled children's parents. Also they used emotion-focused coping strategy than non-disabled children parents. The other coping strategies in both group of parents reported no differences.

\section{REFERENCES}

1. Khamis V. Psychological distress among parents of children with mental retardation in the United Arab Emirates. Social Science \& Medicine. 2007;64(4):850-857

2. Saloviita T, Itaalinna M, Leinonen E. Explaining the parental stress of fathers and mothers caring for a child with intellectual disability: A double ABCX model. Journal of Intellectual Disability Research. 2003; 47(4-5): 300-312.

3. World Health Organization The World Health Report: Mental health: New understanding, new hope. 2001. 
Stress, Depression, Anxiety, And Coping Strategies Of Parents Of Intellectually Disabled And Non-Disabled Children.

[Online] [cited 2001] Available from: http://www.who.int/ whr/2001/en/whr01_en.pdf.

4. Keskin G. The evaluation of anxiety, parental attitude and coping strategy in parents of children with mental retardation. Anatolian Journal of Psychiatry. 2010; 11(1): 30-37.

5. Cramm J, Nieboer A. Psychological well-being of caregivers of children with intellectual disabilities: Using parental stress as a mediating factor. Journal of Intellectual Disabilities. 2011; 15(2):101-113.

6. Woodman AC. Trajectories of stress among parents of children with disabilities: A dyadic analysis. Family Relations. 2014; 63(1): 39-54.

7. Harre R, Lamb R. The Encyclopedic Dictionary of Psychology. Oxford, Blackwell. 1983.

8. American Psychiatric Association [APA]. Diagnostic and Statistical Manual of Mental Disorders (5thed.). Washington, DC 2013.

9. Carver CS, Scheier MF, Weintraub JK. Assessing coping strategies: A theoretically based approach. Journal of Personality and Social Psychology. 1989; 56: 267-283.

10. Lach LM, Kohen DE, Garner RE, Brehaut JC, Miller AR, Rosenbaum PL. The health and psycho-social functioning of caregivers of children with neuro-developmental disorders. Disability and Rehabilitation. 2009; 31: 607618. DOI:10.1080/09638280802242163

11. Das A, Jain P, Kale VP. A cross-sectional study to assess anxiety and depression in parents of children with intellectual disability. Indian J Psychiatry. 2018; 60: S125.

12. Chouhan SC, Singh P, Kumar S. A comparative study of anxiety and depressive symptoms among parents of mentally retarded children. J Well Being. 2016; 10: 17-28.

13. Sheikh MH, Ashraf S, Imran N, Hussain S, Azeem MW. Psychiatric morbidity, perceived stress and ways of coping among parents of children with intellectual disability in Lahore, Pakistan. Cureus. 2018; 10: e2200.

14. Fiorillo D, Sabatini F. Quality and quantity: the role of social interactions in self-reported individual health. Social Science and Medicine. 2011; 73(11): 1644-52. DOI: 10.1016/j.socscimed.2011.09.007
15. Park J, Kitayama S, Karasawa M, Curhan K, Markus HR Kawakami $\mathrm{N}$ et al. Clarifying the link between social support and health: Culture, stress, and neuroticism matter. Journal of Health Psychology. 2012; 18(2): 226-235. DOI: $10.1177 / 1359105312439731 \mathrm{hpq}$. sagepub.com.

16. Von-Gontard A, Backes M, Laufersweiler-Plass C, Wendland C, Lehmkuhl G, Zerres K, Rudnik-Schöneborn S. Psychopathology and familial stress - comparison of boys with Fragile $X$ syndrome and spinal muscular atrophy. Journal of Child Psychology and Psychiatry, and Allied Disciplines. 2002; 43(7): 949-957.

17. Lovibond PF, Lovibond SH. The structure of negative emotional states: Comparison of the depression anxiety stress scales (DASS) with the beck depression and anxiety inventories. Behavior Research and Therapy. 1995; 33(3): 335-343.

18. Carver CS. You want to measure coping but your protocol' too long: Consider the brief COPE. International Journal of Behavioral Medicine. 1997; 4(1): 92-100. doi:10.1207/s15327558ijbm0401-6

19. Judge SL. Parental coping strategies and strengths in families of young children with disabilities. Family Relations. 1998; 47(3): 263-268.

CONFLICT OF INTEREST: Authors declare no conflict of interest

GRANT SUPPORT AND FINANCIAL DISCLOSURE: NIL

\section{AUTHOR'S CONTRIBUTION}

Following authors have made substantial contributions to the manuscript as under

$\begin{array}{ll}\text { Arzeen N: } & \text { Concept, Design, Review } \\ \text { Irshad: } & \text { Concept, Design, Review } \\ \text { Arzeen S: } & \text { Data Collection, Manuscript writing } \\ \text { Shah SM: } & \text { Data Collection, Manuscript writing }\end{array}$

Authors agree to be accountable for all aspects of the work in ensuring that questions related to the accuracy or integrity of any part of the work are appropriately investigated and resolved. 